\title{
Effect of Diabetic Medication on Cardiovascular Risk and Microvascular Complication in Diabetic Patients: Retrospective Cohort Study
}

\author{
Sudhakar Pachiappan ${ }^{1 *}$, Anju Sukumaran ${ }^{2}$, Soni Rose Mathew ${ }^{2}$, Stephy Deena Varghese ${ }^{2}$, Tintu Aloysious ${ }^{2}$ \\ 'Department of Pharmacology and Toxicology, Swamy Vivekanandha College of Pharmacy, Elayampalayam - 637 205, Tiruchengode, Tamil Nadu, India. \\ ${ }^{2}$ Pharm. D, Interns, Department of Pharmacy Practice, Swamy Vivekanandha College of Pharmacy Elayampalayam - 637205, Tiruchengode, Tamil Nadu, \\ India.
}

\section{ARTICLE INFO \\ Article history: \\ Received on: 09/12/2017 \\ Accepted on: 29/01/2018 \\ Available online: 30/03/2018}

\section{Key words:}

Type 2 Diabetes mellitus, microvascular risk, cardiovascular risk, oral antidiabetic drugs, Insulin.

\begin{abstract}
This study was deliberate to evaluate the effects of diabetic medication on micro vascular and macro vascular complications in diabetic patients. In this retrospective study observational data collected from medical records of type 2 diabetic mellitus (T2DM) patients with index oral hypoglycemic medication over the period of 2009 to 2014, by using the medical record department databases of Vivekananda Medical Care Hospital, Tamil Nadu-25. They were categorised into nine groups based on the treatment received such as metformin alone, sulfonylureas alone, sulfonylureas added to metformin, metformin added to sulfonylureas, metformin with insulin added later, sulfonylureas with metformin, metformin and sulfonylureas with insulin added later, sulfonylureas and metformin with pioglitazone added later, sulfonylureas, metformin and voglibose added later. In Cox regression analyses, we estimated comparative risks for mortality due to cardiovascular problems and cardiovascular hospitalization among study cohorts, with metformin monotherapy as the reference group. The results showed that metformin monotherapy shows less cardiovascular and micro vascular events. Sulfonylurea monotherapy shows significant higher CV risk ratio. Initial sulfonylurea mono therapy with later metformin prescription and initial metformin therapy with later sulfonylureas prescription shows higher CV risk ratio as next to the sulfonylurea monotherapy and increased microvascular complication as compared to the metformin monotherapy. In conclusion the microvascular and macrovascular risks are higher in sulfonylurea alone or in combination with other agents as compared to the metformin monotherapy which has low incidence of cardiovascular risk ratio in type 2 diabetic mellitus.
\end{abstract}

\section{INTRODUCTION}

Diabetes mellitus (DM) is defined as a metabolic syndrome characterized by hyperglycemia which results as of blemish in both secretion and action of insulin. Hyperglycemia is associated with microvascular and macrovascular complications like long-standing dysfunction, damage and failure of various organs, especially the eyes, blood vessels, nerves, heart and kidneys; that considerably increase the morbidity and mortality

\section{${ }^{*}$ Corresponding Author}

Sudhakar Pachiappan, Department of Pharmacology and Toxicology, Swamy Vivekanandha College of Pharmacy Elayampalayam, Namakkal-637 205.E-mail:sudhakar00pharma@gmail.com related to the disease (Funnell, 2010; Underwood, 1992; Morrish, 2001). The reason for this is due to an aging, increasing prevalence of obesity and deskbound lifestyle (Williams, 1998).

The global prevalence of diabetes has nearly increased to two fold since 1980 , which is rising from $4.7 \%$ to $8.5 \%$ in the adults. This shows an increase in associated risk factors such as overweight or obesity. In 2012, 1.5 million mortalities were due to diabetes. Higher than optimal blood glucose caused 2.2 million mortalities, by raising the risks of cardiovascular and other disorders. $43 \%$ of these 3.7 million deaths occur before the age of 70 years. World Health Organisation (WHO) says that diabetes will be the $7^{\text {th }}$ foremost cause of death in 2030 (WHO 2016). More than 180 million people worldwide have type 2 diabetes mellitus which is characterized by hyperglycaemia that causes eye, nerve, 
kidney complications and an increased risk for cardiovascular disease. Diabetes is associated with cardiovascular disease doubles the risk of death, (WHO 2008).

To control hyperglycaemia many antidiabetic drugs are available now. The principal endpoint event in most studies on treatment of DM is a reduction of glycated haemoglobin $\left(\mathrm{HbA}_{1 \mathrm{C}}\right)$ levels; more increased amounts of $\mathrm{HbA}_{1 \mathrm{C}}$ are strongly linked with microvascular complications such as retinopathy, neuropathy and nephropathy. $1 \%$ raises in $\mathrm{HbA}_{1 \mathrm{C}}$ is associated with an $18 \%$ increase in the risk of cardiovascular events and 12 to $14 \%$ increase in the risk of mortality (Selvin et al., 2004; Gerstein et al., 2005; Stratton et al., 2000). Moreover, previous studies have shown that reduction in $\mathrm{HbA}_{1 \mathrm{C}}$ results in reduced microvascular problems. Existing treatment approaches are therefore, planned to accomplish near-normal levels of $\mathrm{HbA}_{1 \mathrm{C}}$. Though, decreases of $\mathrm{HbA}_{1 \mathrm{C}}$ have not been found to decrease macrovascular complications (Lancet, 1998; Stolar, 1988).

Reports from previous studies have revealed that recent antidiabetic drugs decrease $\mathrm{HbA}_{1 \mathrm{C}}$ levels but inconsistently increased cardiovascular events or mortality. The choice of antidiabetic agent not only depends on glycemic control, but also on microvascular and macrovascular complications. So this study was intended to evaluate the impacts of diabetic medication on microvascular and macrovascular snags in diabetic patients.

\section{METHODOLOGY}

\section{Study Design}

In this retrospective inception cohort study was intended to assess the effect of diabetic medication over macrovascular and microvascular risk in diabetic patients by using the Medical record department databases of Vivekananda Medical Care Hospital, Tiruchengode, Tamil Nadu-25. Medical records of type 2 diabetic mellitus (T2DM) patients with index oral hypoglycemic medication were collected over the period of 1 January 2009 to 31 December 2014. This study was approved by Institutional Ethical Committee (SVCP/IEC/JAN/2016/06).

\section{Study Population}

These study cohorts comprised of all individuals from 30 years and above aged who were diagnosed with T2DM earlier to December 2014. We then identified all those who were recently treated with Oral hypoglycemic agents (OHAs) during the study period of 1 January 2009 to 31 December 2014. Follow up began on the day after the first prescription of OHAs. Patients with previous records of OHAs treatments in 2008 were not qualified as they were not new OHA user in our study period. We also exclude the patients who were prescribed insulin moreover earlier than or within the 3 months of their first OHA prescription. Selection of study populations were also based on the inclusion and exclusion criteria.

Nine cohorts were included in our study as defined as follows (Fig. 1):

1. Metformin monotherapy: patients treated with metformin alone during the study period, or those treated with metformin with sulfonylureas or other hypoglycemic agents added later (at which point they were censored). Their index date was the date of their original metformin prescription.
2. Sulfonylureas monotherapy: patients treated with sulfonylureas alone during the study period, or those treated with sulfonylureas with metformin or other hypoglycemic agents added later (at which point they were censored). Their index date was the date of their first sulfonylureas prescription. 3. Combination 1: patients treated with metformin with sulfonylureas added later. Their index date was the date of their first sulfonylureas prescription.

4. Combination 2: patients treated with sulfonylureas and metformin added later. Their index date was the date of their first metformin prescription.

5. Combination 3: patients treated with metformin and insulin added later. Their index date was the date of their first insulin prescription.

6. Combination 4: treatment with together sulfonylureas and metformin at same time. Their index date was the date of their first prescription for both.

7. Combination 5: patients treated with metformin and sulfonylureas with insulin added later. Their index date was the date of their first insulin prescription.

8. Combination 6: patients treated with sulfonylureas and metformin with pioglitazone added later. Their index date was the date of their first pioglitazone prescription.

9. Combination 7: patients treated with sulfonylureas, metformin and voglibose added later. Their index date was the date of their first voglibose prescription.

\section{Inclusion criteria}

The study population included individuals who generally attended Vivekananda medical care Hospital at periodic intervals. All patients who were newly diagnosed as diabetes, aged between 30-60 years and recently treated with OHAs in the study phase of 1 January 2009 to 31 December 2014 were eligible for inclusion. Patients who had fasting plasma glucose $(\mathrm{FPG})>6 \mathrm{mmol} / \mathrm{L}$ on two successive mornings, $1-3$ weeks apart and $\mathrm{HbAlc}>6.5 \%$, were eligible for the study. An FPG of $6 \mathrm{mmol} / \mathrm{L}$ and $\mathrm{HbA} 1 \mathrm{c}>6.5 \%$ were included because this was just beyond the greater limit of our normal reference range.

\section{Exclusion criteria}

We excluded the patients under the age of 30 years with type 2 DM past to December 2008. This did not comprise the patients had an obligation for insulin within 3 months, and were therefore defined as patients with type 1 diabetes. Diabetic patients on dialysis or who had previous record of coronary artery diseases (CAD) and congestive heart failure (CHF) at baseline were also excluded. Patients with ketonuria $>3 \mathrm{mmol} / \mathrm{L}$, serum creatinine $>175 \mathrm{mmol} / \mathrm{L}$, myocardial infarction in the earlier year, current angina or heart failure; more than one major vascular event, retinopathy, neuropathy, nephropathy, malignant hypertension and uncorrected endocrine disorders were excluded. We also excluded those records with multiple or missing data.

\section{Data collection}

Data collection includes the baseline medical history such as age, sex, body mass index (BMI), social history (smoking, tobacco chewing, alcohol usage, high salt, high calorie intake and physical inactivity status), systolic and diastolic blood pressure, 
HbAlc, Fasting blood glucose level, postprandial glucose (PPBS), Random blood sugar (RBS) and Lipid profile. These study treatment patients were followed from their index data until censoring, primary risk outcome events, mortality or the end of study phase.

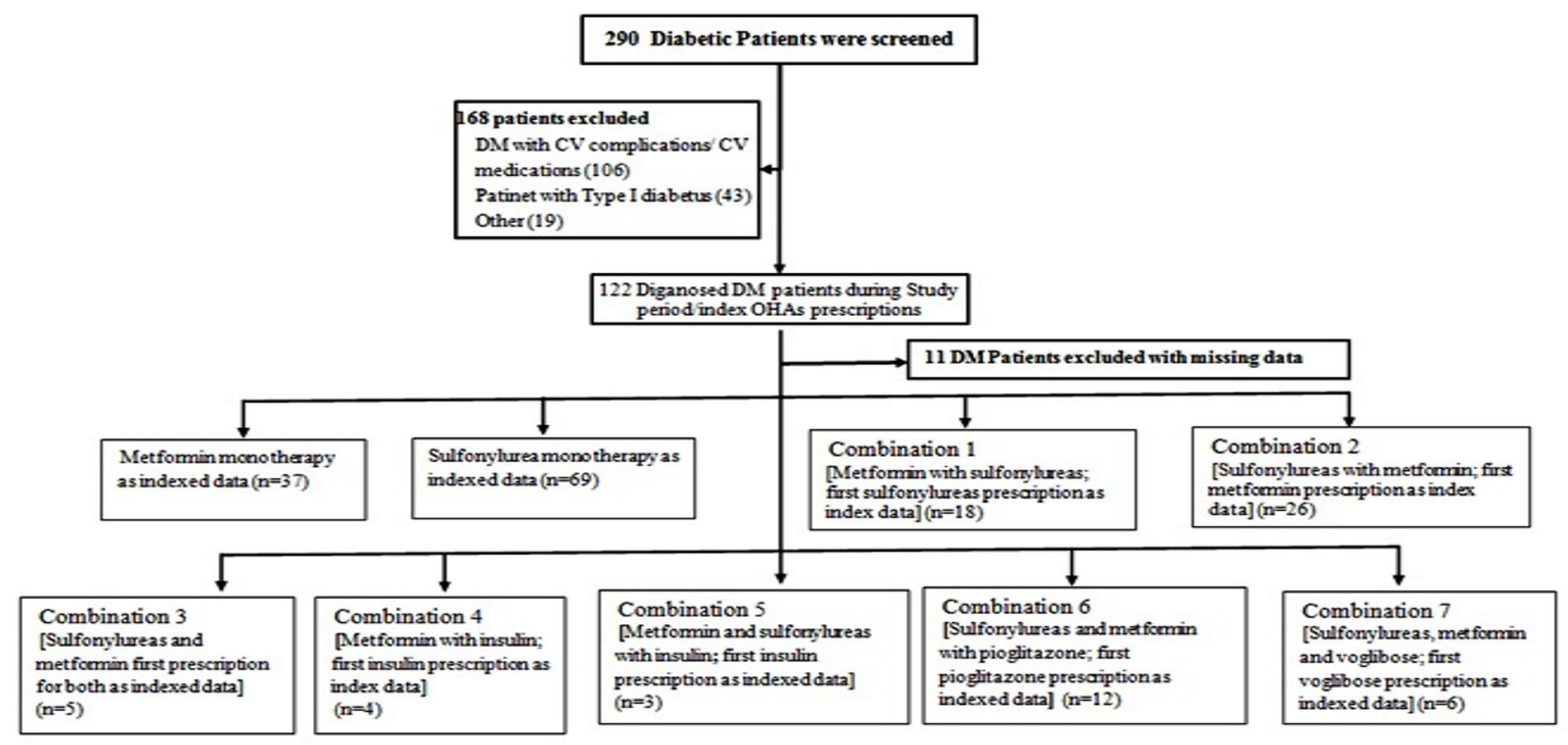

Fig. 1: Trail design.

\section{Primary outcome events}

Primary outcome events were the diagnosis and occurrence of call cause of mortality, primary diagnosis of cardiovascular diseases, composite of Myocardial infarction (MI), stroke or cardiovascular death, presence of neuropathy, nephropathy, retinopathy and dementia.

\section{End point events}

End point measures were the cardiovascular mortality and all causes of mortality or the end of study period of 31 December 2015.

\section{Statistical analysis}

The values were represented as mean $\pm \mathrm{SD}$. Results were analyzed statistically by one way ANOVA followed by post hoc Dunnett's test and unpaired t-test by using SPSS V.17 statistical package. The statistical distinction was considered significant when $\mathrm{P}<0.05$. In order to compare patients in each cohorts, we were used a multivariate analysis that allowed us to adjust the variations in baseline characteristics. Multivariate Cox models were used to derive hazard ratios (HR). Survival curves for CAD, CHF, and mortality were estimated with the Kaplan-Meier procedure.

\section{RESULTS}

A sum of 290 persons with DM were screened in this study, out of which 168 patients were excluded as they were DM with CV complication/taking CV medication or patients with $\mathrm{T}_{1} \mathrm{DM}$. Out of remaining 122 patients, 111 patients with complete demographic and clinical data were available for analysis. The mean age of the 111 patients receiving oral antidiabetes agents were 55.8 years. The overall sex distribution between treatments group were men $52 \%$ and women $48 \%$. Body mass index among the cohorts were ranges from $27.3 \mathrm{~kg} / \mathrm{m}^{2}$ to $31.4 \mathrm{~kg} / \mathrm{m}^{2}$, which was higher in combination7 (Sulfonylurea + Metformin + Voglibose) $31.4 \mathrm{~kg} / \mathrm{m}^{2}$ and least at both Metformin and sulfonylurea treatment cohort. Among this cohorts never smoker, tobacco chewing and alcohol abuse percentage was higher in compare to current and quit patients, as well as social and regular drinkers in alcohol users (Table 1).

There was no significant base line difference in mean $\mathrm{HbA}_{1 \mathrm{c}}$, FPG and PPG levels. At clinical end point mean $\mathrm{HbA}_{1 \mathrm{c}}$ was significantly $(\mathrm{P}<0.05)$ higher in combination $1,2,5$ and 7 as compare to the metformin cohort. FPG was significantly $(\mathrm{P}<$ 0.05 ) higher in combination 1 as compare to the metformin cohort. PPG level was significantly $(\mathrm{P}<0.05)$ higher in combination 1 and 2 as compare to the metformin cohort.

There was no significant baseline distinction in mean LDL, HDL, TG and TC levels. At clinical endpoint sulfonylurea monotherapy shows significant $(\mathrm{P}<0.01)$ increases in LDL as compare to the metformin monotherapy cohort; metformin monotherapy and combination 5 shows significant $(\mathrm{P}<0.01)$ and combination 1 and 4 shows significant $(\mathrm{P}<0.05)$ decrease in LDL level as compare to the sulfonylurea monotherapy. There was no significant difference of HDL at clinical end point in treatment groups. Sulfonylurea monotherapy and combination 1 shows significant $(\mathrm{P}<0.001)$ and combination 2 and 6 shows significant $(\mathrm{P}$ $<0.01)$ increases in TG as compare to the metformin monotherapy cohort; metformin monotherapy shows significant $(\mathrm{P}<0.001)$ and combination 4, 5 and 7 shows significant $(\mathrm{P}<0.01)$ decrease in TG level as compared to the sulfonylurea monotherapy.

Sulfonylurea monotherapy and combination 1, 2, 7 shows significant $(\mathrm{P}<0.001)$ and combination 4 and 6 shows 
significant $(\mathrm{P}<0.01)$ increases in $\mathrm{TC}$ as compare to the metformin monotherapy cohort; metformin monotherapy shows significant $(\mathrm{P}<0.001)$ and combination 3 and 5 shows significant $(\mathrm{P}<0.05)$ decrease in TC level as compared to the sulfonylurea monotherapy cohort (Table 2).
Frequencies of microvascular events are summarized in Table 3. Microvascular event percentages were higher in order of combination 1, 2, sulfonylurea monotherapy, combination 3 and metformin monotherapy.

Table 1: Baseline Demographic characteristics and cardiovascular risk factors of the patients in treatment groups.

\begin{tabular}{|c|c|c|c|c|c|c|c|c|c|}
\hline $\begin{array}{l}\text { Demographic } \\
\text { characteristics }\end{array}$ & MET & SU & $\begin{array}{l}\mathrm{MET}+\mathrm{SU} \\
\quad(\mathrm{C} 1)\end{array}$ & $\begin{array}{l}\text { SU + MET } \\
\text { (C2) }\end{array}$ & $\begin{array}{c}\text { MET \& SU } \\
\text { (C3) }\end{array}$ & $\begin{array}{c}\text { MET + INS } \\
\text { (C4) }\end{array}$ & $\begin{array}{c}\text { MET + SU + } \\
\text { INS (C5) }\end{array}$ & $\begin{array}{l}\text { SU + MET + } \\
\text { PIO (C6) }\end{array}$ & $\begin{array}{c}\text { SU + MET + } \\
\text { VOGL (C7) }\end{array}$ \\
\hline Total $(\mathrm{n}=111)$ & 37 & 69 & 18 & 26 & 5 & 4 & 3 & 12 & 6 \\
\hline Mean age (years) & $56.3 \pm 1.7$ & $54.6 \pm 3.2$ & $57.1 \pm 1.3$ & $55.7 \pm 1.9$ & $55.2 \pm 2.8$ & $52.3 \pm 4.4$ & $54.0 \pm 4.0$ & $58.2 \pm 2.2$ & $59.2 \pm 2.3$ \\
\hline $\operatorname{Sex}(M / F)$ & $21 / 16$ & $35 / 34$ & $8 / 10$ & $14 / 12$ & $2 / 3$ & $1 / 3$ & $2 / 1$ & $6 / 6$ & $2 / 4$ \\
\hline Women $\%$ & 43.2 & 49.3 & 55.6 & 46.2 & 60.0 & 75.0 & 33.3 & 50.0 & 66.7 \\
\hline Mean BMI $\left(\mathrm{kg} / \mathrm{m}^{2}\right)$ & $27.9 \pm 1.4$ & $28.3 \pm 2.3$ & $30.1 \pm 2.8$ & $29.2 \pm 3.2$ & $27.3 \pm 1.5$ & $29.2 \pm 5.3$ & $29.3 \pm 4.2$ & $29.6 \pm 1.6$ & $31.4 \pm 2.8$ \\
\hline $\begin{array}{l}\text { Smoking (\%) } \\
\text { Never/Current/Quit }\end{array}$ & $59.5 / 18.9 / 13.5$ & $60.9 / 17.4 / 8.7$ & $66.7 / 22.2 / 11.1$ & $57.7 / 19.2 / 15.4$ & $60.0 / 20.0$ & $75.0 / 0 / 25.0$ & $66.7 / 33.3$ & $66.7 / 25.0 / 8.3$ & $66.7 / 16.7 / 16.7$ \\
\hline $\begin{array}{l}\text { Tobacco chewing } \\
(\%) \\
\text { Never/Current/Quit }\end{array}$ & $64.9 / 16.2 / 5.4$ & $58.0 / 23.2 / 5.8$ & $61.1 / 22.2 / 5.6$ & $57.7 / 23.1 / 11.5$ & $60.0 / 20.0$ & $75.0 / 0 / 25.0$ & $66.7 / 33.3$ & $66.7 / 16.7 / 8.3$ & $66.7 / 16.7$ \\
\hline $\begin{array}{l}\text { Alcohol (\%) } \\
\text { Non/Social/Reg- } \\
\text { ular }\end{array}$ & $62.2 / 10.8 / 24.3$ & $55.1 / 14.5 / 17.4$ & $55.6 / 16.7 / 22.2$ & $57.7 / 15.4 / 23.1$ & $60.0 / 0 / 40.0$ & $75.0 / 25.0$ & $33.3 / 33.3 / 33.3$ & $50.0 / 25.0 / 16.7$ & $66.7 / 16.7$ \\
\hline $\begin{array}{l}\text { High salt/High } \\
\text { calorie intake (\%) }\end{array}$ & $21.6 / 27.0$ & $18.8 / 27.5$ & $22.2 / 27.8$ & $23.1 / 30.8$ & $20.0 / 40.0$ & $25.0 / 50.0$ & $33.3 / 66.7$ & $33.3 / 58.3$ & $33.3 / 50$ \\
\hline $\begin{array}{l}\text { Physical activity } \\
(\%) \\
\text { Sedentary/Moder- } \\
\text { ately active/Active }\end{array}$ & $8.1 / 37.8 / 40.5$ & $5.8 / 31.9 / 43.5$ & $11.1 / 33.3 / 38.9$ & $11.5 / 26.9 / 46.2$ & $20.0 / 40.0 / 40.0$ & $25.0 / 50.0 / 25.0$ & $66.7 / 33.3$ & $25.0 / 41.7 / 16.7$ & $33.3 / 50.0 / 16.7$ \\
\hline
\end{tabular}

Table 2: The effect of diabetic medication on blood sugar level and lipid profile in treatment groups.

\begin{tabular}{|c|c|c|c|c|c|c|c|c|c|c|}
\hline Para & $\begin{array}{l}\text { meters/Study } \\
\text { Cohorts }\end{array}$ & MET & SU & $\begin{array}{l}\text { MET + SU } \\
\quad \text { (C1) }\end{array}$ & $\begin{array}{l}\text { SU + MET } \\
\quad(\mathrm{C} 2)\end{array}$ & $\begin{array}{l}\text { MET \& SU } \\
\text { (C3) }\end{array}$ & $\begin{array}{l}\text { MET + INS } \\
\text { (C4) }\end{array}$ & $\begin{array}{c}\text { MET + SU + } \\
\text { INS (C5) }\end{array}$ & $\begin{array}{c}\text { SU + MET + } \\
\text { PIO (C6) }\end{array}$ & $\begin{array}{c}\text { SU + MET + } \\
\text { VOGL (C7) }\end{array}$ \\
\hline \multirow{7}{*}{$\begin{array}{l}\text { Baseline } \\
\text { value }\end{array}$} & $\mathrm{HbA}_{1 \mathrm{c}}(\%)$ & $8.5 \pm 1.1$ & $8.4 \pm 1.0$ & $8.9 \pm 1.2$ & $8.3 \pm 1.0$ & $8.4 \pm 1.3$ & $8.8 \pm 1.4$ & $9.3 \pm 1.2$ & $8.7 \pm 1.3$ & $8.7 \pm 1.2$ \\
\hline & $\mathrm{FPG}(\mathrm{mmol} / \mathrm{L})$ & $12.8 \pm 2.1$ & $13.3 \pm 3.6$ & $14.1 \pm 2.5$ & $13.0 \pm 3.2$ & $13.7 \pm 3.7$ & $14.7 \pm 3.4$ & $13.9 \pm 4.2$ & $13.1 \pm 3.3$ & $13.3 \pm 2.9$ \\
\hline & PPG (mmol/L) & $13.2 \pm 1.2$ & $13.4 \pm 1.3$ & $13.8 \pm 3.2$ & $13.2 \pm 4.2$ & $14.3 \pm 5.3$ & $13.5 \pm 3.4$ & $13.2 \pm 2.4$ & $14.0 \pm 3.5$ & $13.8 \pm 4.7$ \\
\hline & LDL (mg/dl) & $132.0 \pm 12.5$ & $134.2 \pm 23.2$ & $136.3 \pm 14.2$ & $135.4 \pm 32.2$ & $133.3 \pm 21.7$ & $134.4 \pm 14.4$ & $140.2 \pm 15.5$ & $138.9 \pm 22.4$ & $141.2 \pm 12.5$ \\
\hline & HDL (mg/dl) & $42.1 \pm 3.4$ & $43.2 \pm 5.2$ & $42.6 \pm 2.4$ & $45.3 \pm 3.6$ & $44.2 \pm 4.3$ & $41.3 \pm 1.2$ & $41.6 \pm 5.3$ & $48.7 \pm 4.8$ & $45.1 \pm 2.3$ \\
\hline & $\mathrm{TG}(\mathrm{mg} / \mathrm{dl}$ & $234.7 \pm 13.3$ & $231.4 \pm 14.9$ & $241.2 \pm 45.1$ & $230.2 \pm 42.1$ & $231.6 \pm 12.2$ & $233.8 \pm 14.5$ & $232.4 \pm 32.2$ & $228.9 \pm 12.4$ & $226.6 \pm 20.2$ \\
\hline & $\mathrm{TC}(\mathrm{mg} / \mathrm{dl})$ & $222.4 \pm 19.2$ & $225.1 \pm 12.7$ & $237.2 \pm 19.4$ & $228.7 \pm 13.4$ & $218.4 \pm 19.7$ & $220.7 \pm 32.5$ & $219.3 \pm 26.3$ & $226.5 \pm 15.4$ & $230.2 \pm 15.2$ \\
\hline \multirow{7}{*}{$\begin{array}{l}\text { End } \\
\text { point } \\
\text { value }\end{array}$} & $\mathrm{HbA}_{1 \mathrm{c}}(\%)$ & $7.3 \pm 0.7$ & $7.6 \pm 0.7$ & $8.0 \pm 0.8^{*}$ & $8.1 \pm 0.7^{*}$ & $7.9 \pm 0.7$ & $7.9 \pm 0.7$ & $8.0 \pm 0.2^{*}$ & $7.8 \pm 0.6$ & $8.0 \pm 0.7^{*}$ \\
\hline & $\mathrm{FPG}(\mathrm{mmol} / \mathrm{L})$ & $10.4 \pm 1.8$ & $11.9 \pm 2.9$ & $12.6 \pm 2.0^{*}$ & $11.6 \pm 3.2$ & $11.9 \pm 3.8$ & $12.2 \pm 3.3$ & $11.7 \pm 4.1$ & $12.1 \pm 3.4$ & $12.2 \pm 2.7$ \\
\hline & PPG (mmol/L) & $11.5 \pm 2.3$ & $11.9 \pm 2.4$ & $13.5 \pm 3.3^{*}$ & $13.6 \pm 2.0^{*}$ & $12.3 \pm 3.2$ & $12.3 \pm 3.2$ & $12.3 \pm 1.9$ & $12.3 \pm 1.6$ & $13.0 \pm 2.4$ \\
\hline & LDL (mg/dl) & $107.2 \pm 12.1^{\mathrm{b}^{* *}}$ & $121.0 \pm 12.4^{\mathrm{a}^{* *}}$ & $108.9 \pm 12.7^{\mathrm{b}^{*}}$ & $116.4 \pm 10.4$ & $108.9 \pm 7.7$ & $107.6 \pm 18.9^{b^{*}}$ & $104.2 \pm 16.4^{\mathrm{b}^{* *}}$ & $109.4 \pm 12.1$ & $109.7 \pm 15.6$ \\
\hline & HDL (mg/dl) & $43.2 \pm 3.2$ & $39.8 \pm 2.5$ & $41.3 \pm 5.6$ & $43.2 \pm 4.2$ & $43.1 \pm 3.4$ & $40.2 \pm 8.2$ & $41.3 \pm 4.8$ & $46.5 \pm 2.9$ & $44.8 \pm 3.4$ \\
\hline & $\mathrm{TG}(\mathrm{mg} / \mathrm{dl})$ & $195.8 \pm 13.6^{\mathrm{b}^{* * *}}$ & $223.3 \pm 15.4^{4^{* * *}}$ & $232.1 \pm 23.9^{\mathrm{a}^{* * *}}$ & $215.8 \pm 11.2^{\mathrm{a}^{* *}}$ & $207.7 \pm 21.4$ & $198.8 \pm 9.0^{\mathrm{b}^{* * *}}$ & $199.3 \pm 13.1^{\mathrm{b}^{* *}}$ & $213.7 \pm 18.4^{\mathrm{a}^{* *}}$ & $201.2 \pm 11.5^{\mathrm{b}^{* *}}$ \\
\hline & $\mathrm{TC}(\mathrm{mg} / \mathrm{dl})$ & $197.9 \pm 12.9^{b^{* * *}}$ & $221.8 \pm 12.8^{\mathrm{a}^{* * *}}$ & $225.8 \pm 25.1^{\mathrm{a}^{* * *}}$ & $222.0 \pm 15.0^{\mathrm{a}^{* * * *}}$ & $201.9 \pm 12.1^{\mathrm{b}^{*}}$ & $211.9 \pm 10.2^{\mathrm{a}^{* *}}$ & $203.0 \pm 6.4^{b^{*}}$ & $215.8 \pm 9.4^{\mathrm{a}^{* *}}$ & $220.5 \pm 12.2^{\mathrm{a}^{* * *}}$ \\
\hline
\end{tabular}

Values are expressed as mean $\pm \mathrm{SD}$.

Comparisons were made between: a- Metformin Vs others; b- Sulfonylureas Vs others,

Symbols represent statistical significance: $* * *-\mathrm{P}<0.001,{ }^{*}$ - $\mathrm{P}<0.01,{ }^{*}-\mathrm{P}<0.05$.

The number of patients in every cohort who had cardiovascular outcomes is represented in Table 4, with unadjusted risk ratios. We found that $5.0 \%$ of patients in metformin monotherapy showed cardiovascular death, compared with $17 \%$ (3.01 of RR) of patients in sulfonylurea monotherapy, $15 \%$ (2.04 of RR) of patients with combination $2,11 \%$
(1.90 of RR) of patients with combination 1. Primary outcome event was $33 \%$ (1.5 of RR) of patients with combination $1,31 \%$ (2.3 of RR) of patients with combination $2,20 \%$ (1.2 of RR) of patients with combination 3, 23\% (1.6 of RR) of patients with combination 6 and $33 \%$ (1.7 of RR) of patients with combination 7 cohort. 


\section{DISCUSSION}

Our study represents observational data from medical records of type 2 diabetic mellitus (T2DM) patients with index oral hypoglycemic medication were collected over the period of 1 January 2009 to 31 December 2014, by using the medical record department databases of Vivekananda Medical Care Hospital, Tiruchengode, Tamilnadu-25. Observed data in our study from general practice allows evaluation of the essential benefits and hazards of use of diabetic medication at $\mathrm{CV}$ risks associated with DM.

Table 3: Frequencies of microvascular and macrovascular events.

\begin{tabular}{|c|c|c|c|c|c|c|c|c|c|}
\hline Events & MET & SU & $\begin{array}{c}\mathrm{MET}+\mathrm{SU} \\
\quad \text { (C1) }\end{array}$ & $\begin{array}{c}\text { SU + MET } \\
\text { (C2) }\end{array}$ & $\begin{array}{c}\text { MET \& SU } \\
\text { (C3) }\end{array}$ & $\begin{array}{c}\text { MET + INS } \\
\text { (C4) }\end{array}$ & $\begin{array}{l}\text { MET + SU } \\
+ \text { INS (C5) }\end{array}$ & $\begin{array}{l}\text { SU + MET } \\
+ \text { PIO (C6) }\end{array}$ & $\begin{array}{c}\text { SU + MET } \\
+ \text { VOGLI } \\
\text { (C7) }\end{array}$ \\
\hline Neuropathy (\%) & 3 & 9 & 14 & 12 & 20 & - & - & 8 & 17 \\
\hline Nephropathy (\%) & 3 & 7 & 17 & 19 & - & - & - & 17 & - \\
\hline Retinopathy (\%) & - & 3 & 5 & 8 & - & - & - & - & - \\
\hline Dementia $(\%)$ & 3 & 3 & 11 & 15 & - & - & - & 17 & 17 \\
\hline Primary diagnosis $\mathrm{CV}$ disorders $(\%)$ & 8 & 13 & 22 & 23 & 20 & 25 & 33 & 25 & 17 \\
\hline Cardiac dysrhythmia (\%) & 3 & 4 & 6 & 4 & - & - & - & 8 & - \\
\hline MI (\%) & 3 & 3 & 6 & 4 & - & - & - & 8 & 17 \\
\hline Stroke or Cardiovascular death (\%) & 5 & 17 & 11 & 15 & 20 & - & - & 25 & 17 \\
\hline
\end{tabular}

Table 4: The unadjusted risk ratio (with 95\% CIs) for cardiovascular mortality and cardiovascular admission for the patients in the study cohorts.

\begin{tabular}{|c|c|c|c|c|}
\hline \multirow{2}{*}{ Study Cohort } & \multicolumn{2}{|c|}{ Cardiovascular mortality } & \multicolumn{2}{|c|}{ Cardiovascular admission } \\
\hline & RR $(95 \%$ CI $)$ & Events/total (\%) & RR $(95 \%$ CI $)$ & Events/total (\%) \\
\hline MET & 1.00 (referent) & $2 / 37(5 \%)$ & 1.00 (referent) & $5 / 37(14 \%)$ \\
\hline SU & $3.01(2.7-3.3)$ & $12 / 69(17)$ & $1.12(0.8-1.9)$ & $18 / 69(26 \%)$ \\
\hline $\mathrm{ET}+\mathrm{SU}(\mathrm{C} 1)$ & $1.90(1.4-2.3)$ & $2 / 18(11 \%)$ & $1.50(0.7-2.1)$ & $6 / 18(33 \%)$ \\
\hline $\mathrm{SU}+\mathrm{MET}(\mathrm{C} 2)$ & $2.04(1.7-2.5)$ & $4 / 26(15 \%)$ & $2.30(1.3-2.9)$ & $8 / 26(31 \%)$ \\
\hline $\mathrm{MET}+\mathrm{SU}(\mathrm{C} 3)$ & $1.70(1.2-2.1)$ & $1 / 5(20 \%)$ & $1.20(0.7-1.8)$ & $1 / 5(20 \%)$ \\
\hline MET + INS (C4) & - & $0 / 4(0)$ & - & $1 / 4(25 \%)$ \\
\hline $\mathrm{MET}+\mathrm{SU}+\mathrm{INS}(\mathrm{C} 5)$ & - & $0 / 3(0)$ & - & $1 / 3(33 \%)$ \\
\hline $\mathrm{SU}+\mathrm{MET}+\mathrm{PIO}(\mathrm{C} 6)$ & $1.60(1.5-1.9)$ & $3 / 12(25 \%)$ & $1.60(0.8-2.1)$ & $5 / 12(23 \%)$ \\
\hline $\mathrm{SU}+\mathrm{MET}+\operatorname{VOGL}(\mathrm{C} 7)$ & $1.80(1.4-2.2)$ & $1 / 6(17 \%)$ & $1.70(1.2-2.3)$ & $2 / 6(33 \%)$ \\
\hline
\end{tabular}

RR-Risk ratios.

Persons with T2DM are at high risk of $\mathrm{CV}$ morbidity and mortality. Some of previous studies report that almost $75 \%$ of patients with T2DM were died due to macrovascular events, such as MI and stroke. (Bo et al., 2006). In this study, persons with T2DM who were recently prescribed with sulfonylureas monotherapy, later metformin prescription; initial metformin therapy with later sulfonylureas prescription; initial sulfonylurea monotherapy with later prescription of metformin and voglibose were at higher risk of cardiovascular mortality and cardiovascular admission when compared to the patients who were newly prescribed with metformin. The unadjusted risk ratio of CV mortality were 3.01 (95\% CI 2.7-3.3) at sulfonylurea monotherapy, 2.04 (95\% CI 1.7-2.5) at later metformin prescription, 1.90 (95\% CI 1.4-2.3) at initial metformin therapy with later sulfonylureas prescription, 1.80 (95\% CI 1.4-2.2) at initial sulfonylurea monotherapy with later prescription of metformin and voglibose. It is consisted with previous studies that found patients treated with metformin where at lower cardiovascular risk (Evans et al., 2006).

The increased risk of CV morbidity and mortality linked with diabetes has lead to the perception that hyperglycaemia may be one of the risk factor for CVD (Kuusisto et al., 1994; Haffner and Cassells, 2003; Takahashi et al., 2006). The UK prospective study reported that each $1 \%(<6 \%$ to $\geq 10 \%)$ diminution in $\mathrm{HbA}_{1 \mathrm{c}}$ was linked with a reduction in risk of $21 \%$ for any diabetic end point death and $14 \%$ for MI (Stratton, 2000). In this study the level of $\mathrm{HbA}_{1 \mathrm{c}}$ shows significant increases in initial metformin therapy with later sulfonylureas prescription (C1); initial sulfonylurea monotherapy with later prescription of metformin (C2) and initial sulfonylurea monotherapy with later prescription of metformin and voglibose (C7) cohort as compared to the metformin monotherapy. This may be one of the risk factor which may increases the macrovascular and microvascular risk in those cohorts.

Postprandial glucose control also plays a considerable role in overall glycemic control and became more essential 
than fasting plasma glucose when better control is achieved (Monnier et al., 2003). In this study PPG and FPG level shows significantincreases in initial metformin therapy with later sulfonylureas prescription (C1) and PPG level was also significantly higher in initial sulfonylurea monotherapy with later prescription of metformin (C2). This may be one of accompanying risk factor for the cardiovascular and microvascular risk in those cohorts.

The mechanism by which enhanced glycemic control reduces cardiovascular risk are not absolutely unstated, but probably related to the betterment of dyslipidemia, endothelial dysfunction, vasomotor dysfunction, and coagulation malfunction all of which are aggravated by hyperglycemia (Avena et al., 1998; Mather et al., 2001). This study shows that LDL, TG, and TC level was moderately decreased in Metformin monotherapy as compare to the other treatment cohort. This may confirm the cardio protective property of the metformin.

Total cholesterol and triglyceride level in sulfonylurea monotherapy; initial metformin therapy with later sulfonylureas prescription (C1); initial sulfonylurea monotherapy with later prescription of metformin (C2) and initial sulfonylurea monotherapy with later prescription of metformin and pioglitazone cohorts were significantly higher as compared to the metformin monotherapy. This may confirm the cardio toxic property of these combinations.

\section{CONCLUSION}

This retrospective cohort study was carried out in 111 patients who were newly diagnosed with DM and their index treatment of Metformin, sulfonylurea or both at the study site of Vivekananda Medical Care Hospital, Tiruchengode, Tamilnadu-25. Metformin monotherapy cohort showed less cardiovascular and micro vascular events when compared to the other cohorts. It may be due to the significant reduction action against blood sugar and lipid profile in T2DM patients. Sulfonylurea monotherapy cohort is the most prescribed medication among this population; it showed significant higher $\mathrm{CV}$ risk ratios when compared to the other cohorts. Initial sulfonylurea mono therapy with later metformin prescription (C2) and initial metformin therapy with later sulfonylureas prescription $(\mathrm{C} 1)$ cohort showed higher $\mathrm{CV}$ risk ratio as next to the sulfonylurea monotherapy and higher percentage of microvascular complication as compared to the metformin monotherapy cohort. Combination 3, 4 and 5 cohort included study populations were not showed significant difference in our study so it was difficult to assess macrovascular and microvascular complication in these treatment cohorts. At initial sulfonylurea monotherapy with later prescription of metformin and pioglitazone or voglibose showed milder incidence of macrovascular and microvascular complication when compared to metformin monotherapy.

In conclusion the microvascular and macrovascular risks are higher in sulfonylurea monotherapy or in combination with other agents when compared to the metformin monotherapy, which has low incidence of risk ratio in type 2 diabetic mellitus cohorts.

\section{REFERENCE}

Avena R, Mitchell ME, Nylen ES, Curry KM, Sidawy AN. Insulin action enhancement normalizes bronchial artery vasoactivity in patients with peripheral vascular disease and occult diabetes. J Vasc Surg, 1998;
28(6):1024-1032. doi: http://dx.doi.org/10.1016/S0741-5214(98)70028-X.

Bo S, Ciccone G, Gancia R, Rosato R, Grassi G, Merletti F, Pagano GF. Mortality within first 10 years of the disease in type 2 diabetic patients. Nur Metab Cardiovasc Dis, 2006; 16(1):8-12. doi: http://dx.doi. org/10.1016/j.numecd.2005.01.003.

Evans JM, Ogston SA, Emslie-Smith A, Morris AD. Risk of mortality and adverse cardiovascular outcomes in type 2 diabetes: a comparison of patients treated with sulfonylureas and metformin. Diabetologia, 2006; 49(5):930-936. doi 10.1007/s00125-006-0176-9.

Funnell MM. American Diabetes Association. Diagnosis and classification of Diabetes Mellitus. Diabetes Care, 2010; 33 (1): 62-69.

Gerstein HC, Pogue J, Mann JF, Lonn E, Dagenais GR, McQueen M, Yusuf S, HOPE investigators. The relationship between dysglycaemia and cardiovascular and renal risk in diabetic and non-diabetic participants in the HOPE study: a prospective epidemiological analysis. Diabetologia, 2005; 48 (9):1749-1755.

Global report on diabetes. Geneva: World Health Organization;

2016.

Haffner SJ, Cassells H. Hyperglycemia as a cardiovascular risk factor. Am J Med, 2003; 115(8):S6-11.

Intensive blood-glucose control with sulphonylureas or insulin compared with conventional treatment and risk of complications in patients with type 2 diabetes (UKPDS 33). UK Prospective Diabetes Study (UKPDS) Group. Lancet, 1998; 352(9131):837-853.

Kuusisto J, Mykkanen L, Pyorala K, Laakso M. NIDDM and its metabolic control predict coronary heart diseases in elderly subjects. Diabetes, 1994; 43(8):960-967.

Mather KJ, Verma S, Anderson TJ. Improved endothelial function with metformin in type 2 diabetes mellitus. J Am Coll Cardiol, 2001; 37(5):1344-1345. doi: https://doi.org/10.1016/S0735-1097(01)01129-9

Monnier L, Lapinski H, Colette C. Contribution of fasting and post prandial plasma glucose increments to the overall diurnal hyperglycemia of type 2 diabetic patients. Diabetes Care, 2003; 26(3):881885. doi: https://doi.org/10.2337/diacare.26.3.881.

Morrish NJ, Wang SL, Stevens LK, Fuller JH, Keen H. Mortality and causes of death in the WHO Multinational Study of Vascular Disease in Diabetes. Diabetologia, 2001; 44(2):S14-21.

Selvin E, Marinopoulos S, Berkenblit G, Rami T, Brancati FL, Powe NR, Golden SH. Meta-analysis: glycosylated hemoglobin and cardiovascular disease in diabetes mellitus. Ann Intern Med, 2004; 141(6): 421-431.

Stolar MW. Atherosclerosis in diabetes: the role of hyperinsulinemia. Metabolism, 1988; 37(2):1-9.

Stratton IM, Adler AI, Neil HA, Matthews DR, Manley SE, Cull CA, Hadden D, Turner RC, Holman RR. Association of glycaemia with macrovascular and microvascular complications of type 2 diabetes (UKPDS 35): prospective observational study. BMJ, 2000; 321(7258):405-412.

Takahashi F, Hasebe N, Kawashima E, Takehara N, Aizawa Y, Akasaka K, Kawamura Y, Kikuchi K. Hyperinsulinemia is an independent predictor for complex atherosclerotic lesion of thoracic aorta in nondiabetic patients. Atherosclerosis, 2006; 187(2):336-342. doi: http://dx.doi. org/10.1016/j.atherosclerosis.2005.05.041

Underwood JCE. General and Systematic Pathology. Churchill Livingstone, Edinburgh 1992. doi: 10.1111/j.1365-2559.1993.tb00147.x Williams G. Handbook of Diabetes. Oxford: Blackwell Science Inc, 1998.

World Health Organization. Diabetes, 2008. www.who.Int/ mediacentre /factsheets/ fs312/en/index.html.

How to cite this article:

Pachiappan S, Sukumaran A, Mathew SR, Varghese SD, Aloysious T. Effect of Diabetic Medication on Cardiovascular Risk and Microvascular Complication in Diabetic Patients: Retrospective Cohort Study. J App Pharm Sci, 2018; 8(03): 031036. 